\title{
How to Measure Herd Behavior on the Credit Market?
}

\author{
Dmitry Vladimirovich Burakov \\ Financial University under the Government of Russian Federation \\ Email: dbur89@yandex.ru
}

\section{Doi:10.5901/mjss.2014.v5n20p516}

\section{Abstract}

In this article we present a technique for estimating the effect of herd behavior in case of granting loans on the market for corporate lending. Given that expert opinion as well as bounded rationality plays a key role in the process of decision making on a credit application's approval, overestimation of other players' actions may have a potential for worsening the quality of corporate loans portfolio of a commercial bank. In order to mitigate such an effect it is proposed to use the developed indicators as an additional tool in evaluating a loan application. Also in the result of the carried out research we've revealed a crosscountry pattern of herding effect's development on the credit market: the better the quality of national market's institutions the stronger is the coordination of credit market players in form of herd behavior. One of explanations of the revealed paatern may be linked with the competition issue on the credit market.

Keywords: credit market; corporate lending; bounded rationality; herd behavior; credit risk

\section{Introduction}

Nonoptimality of existing methods of credit risk assessment raises the sustainability of the overdue debts and loan losses as well as procyclical nature of their movement. On the upward phases of the credit cycle, underestimation of credit risk results in its excessive accumulation.

The solution to this problem is directly connected, on the one hand, with improving the quality of theoretical notions about credit risk, on the other - with optimization of methods of its management. Unfortunately, at present only the second aspect of this issue has attracted attention of many researchers and experts in the world. The need to adapt the theoretical framework in line with the existing realities unfortunately has been sidelined. One of the main gaps in this case is the number of non-viable assumptions that offset a large part of the effort.

First of all, it is considered that the massive realization of credit risk in commercial banks is disposable through the improvement of credit risk's management. This postulate is based on the basic assumptions of the neoclassical paradigm of economic thought, for example, on the assumption of full rationality of economic entities. With regard to the activity of commercial banks, this thesis allows us to perceive the process of assessing credit risk, as the process related to having access to existing information on the issue; connected with the rational (effective) use of all the information (i.e. value of one or another piece of information on the issue is equal to all the others when making decisions, and particular experience of decision maker is taken into account in proportion to the rest). Regarding the first requirement, one may notice that the imperfections of the credit market, caused to life by informational asymmetry present by themselves an important obstacle to make a fully informed decision.(Stiglitz \& Weiss, 1981; Burakov, 2014a; Burakov, 2014b) The second requirement in most cases is not confirmed in practice, due to the bounded rationality of decision-makers. (Kahneman \& Tversky, 2008) It is nonoptimality of decision-making process in part of the evaluation of credit risk which is an important factor of its underestimation or consiousc excessive risk taking. (Haldane, 2010; Rotheli, 2012) Due to development of behavioral economics these features became visible much clearer.

For example, recent studies have shown that the evolution of methods of credit risk assessment does not contribute to the optimization of the quality of credit risk management, and in some cases, innovations in credit risk management serve a factor, spurring increased willingness to accept credit risk. (Rotheli, 2012; Burakov, 2014c)

\section{Literature Review}

Among others, one of the main factors that increase the acceptance of credit risk and/or gives birth for its excessive acceptance is the so-called effect of the group behavior or herd behavior effect. The manifestation of this effect has been studied many times and in various areas of daily and business issues. (Banerjee, 1992; Raafat et. al, 2009) However, 
modern risk management in commercial banks pays insufficient attention to the assessment of the psychological features of decision-making process which are thought to be also an important cause of loan losses on the credit market. Moreover, given that the dynamics of credit risk is fundamental in explaining the credit cycle's phenomena (Burakov, 2014d), and that control of the latter is an important task for ensuring stable development of the credit market, the issue of identifying the channels of herd behavior and quantitative methods of its estimation, is of vital importance.

Given the above, the purpose of this study is to identify allocation channels of herd behavior through which it manifests in the behavior of commercial banks; to develope indicators to measure each of these channels and determine the degree of "herding" behaviour of commercial banks on the credit market.

Among the main methods that are used today to describe the studied effect methods of quantitative analysis are prevalent: the use of standard deviation and values of dispersion. A number of studies presents and tests different quantitative assessment techniques of herd behavior of assets markets' participants. (Scharfstein \& Stein, 1990; Hwang \& Salmon, 2001)

Unfortunately, research papers representing estimation of this effect in the sphere of credit relations are scarce. (Haldane et. al., 2010) Methods used in these models are subject to considerable criticism in connection with their ambivalence. (Haldane et. al., 2010) For example, the evaluation of the effect of group dynamics in banking credit market is reduced, in some cases, to evaluation of the variance of return on equity. Given the fact that the income of commercial banks can be derived from many sources, this indicator does not have significant probative force: in this case it is not necessarily reflect herd behaviour in credit activity of banks.

Taking into consideration the existing experience and disadvantages of current developments, we are trying to improve measures of evaluation based on the use of existing approaches to the analysis.

\section{Research Methodology}

\subsection{Theoretical assumptions and an empirical model of herd behavior channels}

Building on existing achievements in this field of research, we introduce a number of assumptions on which identification of the herd behavior is based:

Assumption 1. Commercial banks tend to optimize their financial performance.

Assumption 2. The decision making process regarding the assessment of credit risk and granting loans is characterized by bounded rationality of the subjects.

Given these assumptions, assessment of herd behaviour degree on the credit market should be connected with the manifestation of symmetry in behavior. The identification of this symmetry should be connected with the search of channels through which credit activity of commercial banks could be characterized and a system of incentives for the emergence of herd behavior could be found.

Then, one can select the following channels, allowing to estimate the studied effect:

1. balance sheet channel, which reflects the degree of dependence of one bank's actions from the other, based on a high elasticity level of investors function. Its effect rises because of the need for commercial banks to maintain an appropriate level of profitability (the market average). When targets are not achieved, there is a risk of investors drawing funds from commercial bank and, as a result, adecline in the market value of the bank's shares;

2. credit channel, which reflects the degree of dependence of one bank's credit policy from the other, depending on the level of competitive pressure on credit market.

For the quantitative reflection of the balance sheet channel it's proposed to use the formula for the dispersion of values, to assess the degree of dispersion of the resulting values of commercial banks'activity:

$\mathrm{Chb}=\frac{\sum\left(x_{t}-\bar{x}\right)^{2}}{n-1}$

$\mathrm{n}$ is the sample size (the number of bank credit organizations that make up the pool for analysis), $x t$ - value of return on equity (assets) of banking credit organization for the period t;

$\mathrm{x}$ - average return on equity (assets) of banking credit organizations included in the sample;

Then, the value of the variance of the chosen values to quantify is the criterion for determining the degree of herding behaviour in the banking sector or individual credit organization, reflecting the spread or the concentration values. The case of low values of dispersion can be considered as an argument of herd behavior presented in activities of commercial banks, and this feature deserves attention in the part of analysis and consideration of credit risks taken by commercial banks. In the case of high values of dispersion dependence of one bank's activities from the actions of others 
is not significant and they don't seriously impact on the willingness to accept credit risk on the credit market.

For the quantitative reflection of the credit channel it's proposed to use the technique of averaging, which implies identifying the trend in the activity of credit organizations and determining a position of the analyzed commercial bank in relation to the market:

$\mathrm{Chc}=\frac{\sum_{i=2}^{k} L c}{k}$

$\sum$ LC - the sum of the monthly growth rates (basic period - the previous month of the current year) of loans granted to non-financial sector by banking organizations included in the sample;

$\mathrm{k}$ - the total number of credit organizations included in the sample.

According to the results of the calculation an average growth rate for a specific time period t can be formed (in our case - 1 month). By extrapolating the results for the remaining time periods, one can generate time series, comprising of a set of average values. This line will represent the general trend of the movement of a credit market.

Defining the position of individual commercial bank and independence of its credit policy from the herd effect is defined within a specified time period (1 month) in the following way:

$\mathrm{Pb} 1=\frac{L c 1}{C h c}$,

Lc1 - value of the monthly growth rate of loans granted to non-financial sector by commercial bank; Chc - average growth rates of loans granted to non-financial sector by credit institutions included in the sample.

To determine the presence or absence, as well as the impact of the effect of herd effect on the credit policy of the commercial bank, one should establish thresholds, allowing to estimate this effect.

Assuming that the position of the commercial bank as the ratio of the rates of growth of the portfolio to the mean of growth rate of the portfolio on the market is a quantitative value, we assume that the mean value equals 1 , when the growth rate of the portfolio of a commercial bank is identical to the average value in the market. Given the likelihood of an error and impact of exogenous variables that influence the activities of all of the commercial organizations we poin out the range of tolerance to random deviations from the detectable effect. Thresholds include upper bounds and lower bounds and are determined as $20 \%$ deviations of the values of the growth rates of the portfolio of the commercial bank from the average on the market (1).

Thus, the growth rates lying within the borders may be interpreted as the likelihood of a high degree of herding behavior of commercial banks; the position out of the boundaries indicates the relative independence of the ongoing credit policy from the actions of other players.

\section{Findings and Discussion}

\subsection{Threshold analysis results: balance sheet channel}

In order to determine the thresholds, allowing estimating the impact of the effect of group behavior, it was necessary to carry out the analysis with the use of the developed indicators on actual data. We took appropriate statistical time series within the framework of cross-country slice. Correlation analysis of the dispersion of the values of the profitability of the country's largest commercial banks, which account for over $50 \%$ of the loaned funds (Fig. 1), shows that as the economic system of the country and its credit market develops the effect of herd behavior increases.

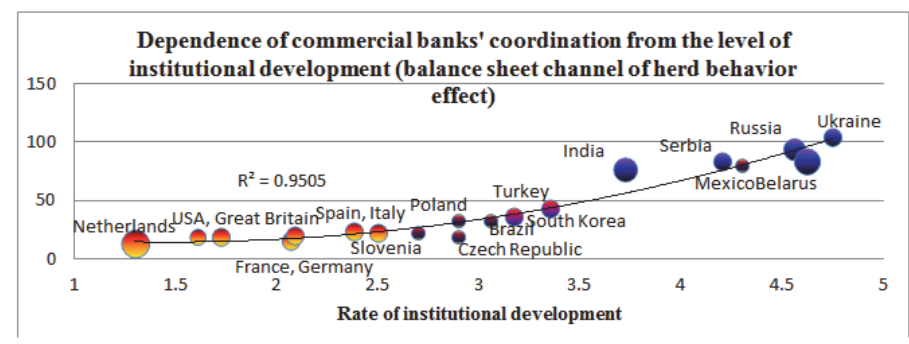

Figure 1. Patterns of Herd Behavior Evolution: Cross-Country Evidence

One of the most often-cited reasons for such pattern is competitive pressure on the credit market. $[6,7]$ 
The data of Figure 2 reflects the degree of correlation between the credit policies of the largest commercial banks of the Russian Federation on the example of volumes of loans granted to non-financial sector.

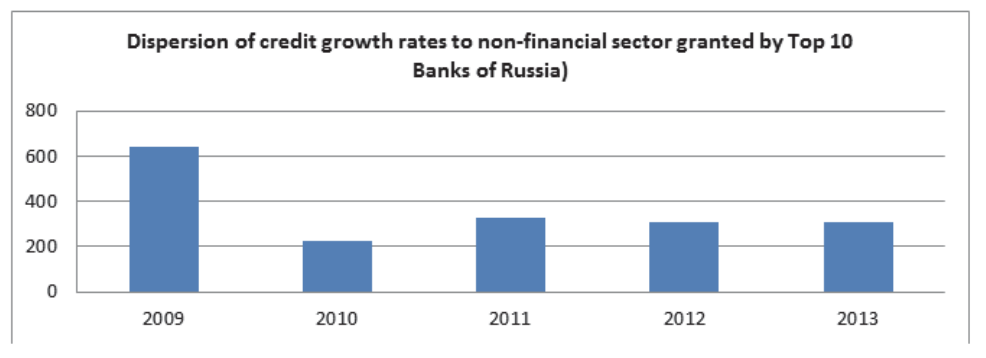

Figure 2. Results of the Herd Behavior Effect Test

Judging by the results of dispersion analysis we can't talk about "herding" behaviour of the Russian lenders. The values of dispersion are over 60 units, which allow speaking about a complete fragmentation and independence of the credit policy on the market for corporate loans. Especially clear this was evidenced during the last crisis (in 2009 the variance value amounted to 643 units). However, in conditions of favorable macroeconomic conditions and the emergence of increased profit rates in certain sectors, the effect may show itself. (Table1)

Thus, on the basis of this analysis, we can try to classify the amplitude of the studied effect in three groups

The first group includes bank credit markets, characterized by a high degree of coordination and, as a consequence, herding in credit activities. The threshold values of dispersion are set at the level of 0 to 25 units. The second group includes bank credit markets, characterized by a moderate level of coordination with the threshold of 25 to 60 units. The features of such credit markets are similar to fast developing countries: increasing competition and decreasing free niches in the market. The third group includes transitive economies slowly turning on "market rules", which are characterized by weak institutional infrastructure, low elasticity of national markets and their extreme concentration. Among features of the credit market, we can point out can low level of competition, low elasticity of demand for credit and the high share of the state in the economic system. The threshold for this group is from 60 units and higher.

Table 1. Threshold Values of Herd Behavior Effect

\begin{tabular}{|c|c|}
\hline Level of herd behavior on credit market & Threshold dispersion value \\
\hline High & $0-25$ \\
\hline Moderate & $25-60$ \\
\hline Low & over 60 \\
\hline
\end{tabular}

\subsection{Threshold analysis results: credit channel}

In order to assess the potential impact of the effect of herd behavior on the level of accepted credit risk, we have tested the proposed indicators on the actual data of a number of commercial banks in Russia. The sample included the largest commercial banks with the biggest portfolios of loans granted to non-financial institutions. On the example of "Sberbank of Russia" and "VTB Bank" we calculated threshold values of the credit channel of coordination to identify presence (absence) of herding in credit activity (Fig. 3, 4, 5). 


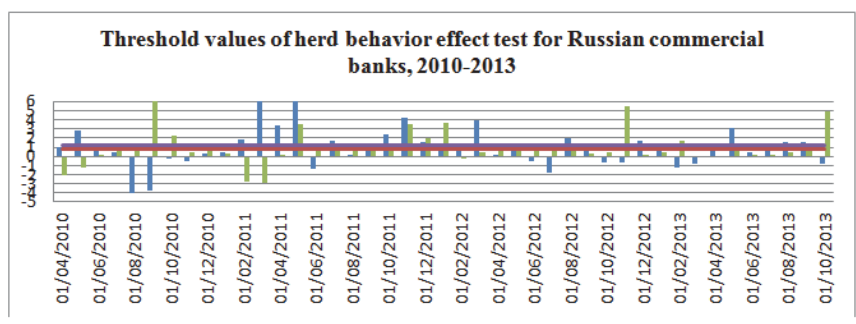

Figure 3. Results of the Herd Behavior Effect Test for Russian Commercial Banks

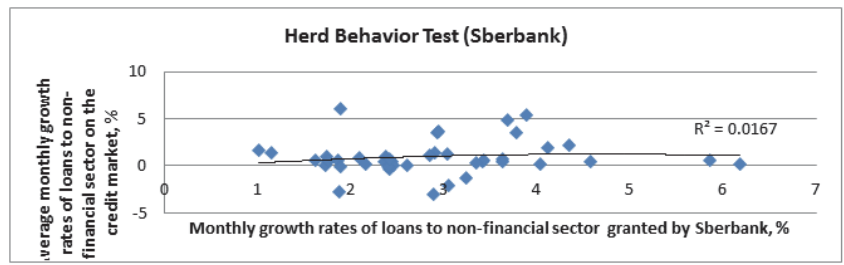

Figure 4. Results of the Herd Behavior Effect Test for Russian Commercial Banks

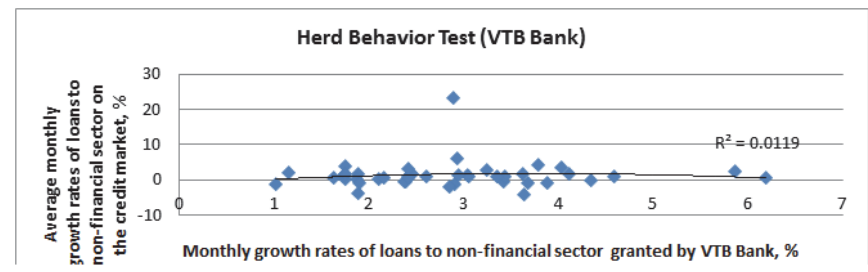

Figure 5. Results of the Herd Behavior Effect Test for Russian Commercial Banks

The results of calculations show that over three years of lending to the nonfinancial sector, the deviation from the average on the market for these two banks is significant and does not fit into the threshold value, which indicates a relatively high degree of credit activities independence on the credit market in relation to the average trend. This independence is mainly due to the dominant position on the market and the status of leaders in lending policy and its direction.

At the same time such independence for other banks should not be thought of as the norm (Fig. 6). According to the threshold analysis of "Alfa Bank", the number of periods of credit policy being within the threshold values is significant, which indicates the presence of certain factors affecting the credit policy of the bank, resulting in the approximation to the average market values; in other words, credit behavior being affected by other players Also this thesis is confirmed by the data of the correlation analysis (Fig. 6). If for banks with state presence in the capital the average value of the approximation coefficient is less than 0,02 for "Alfa-Bank" this value equals 0,1555.

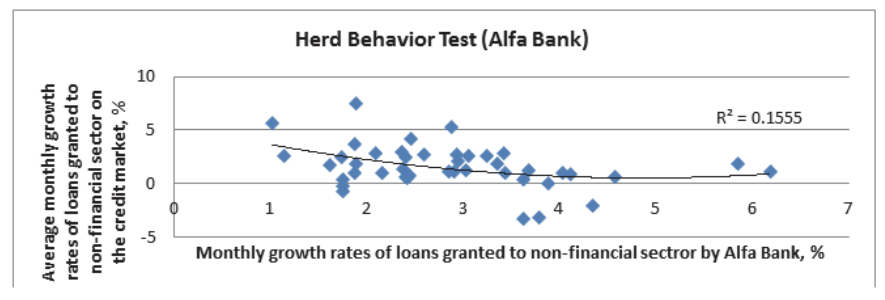

Figure 6. Results of the Herd Behavior Effect Test for Russian Commercial Banks 


\section{Concluding Remarks}

In the result of this research, we were able to confirm the importance of the effect of herd behavior on the credit market and its impact on the attitude toward credit risk.

In particular, we identified two main channels through which coordination of activities of commercial banks.manifests itself. Balance sheet channel reflects the dependence of creditors' actions from each other, due to the high elasticity of investors' function. Credit channel shows the dependence of credit policy of a commercial bank from actions of competitors and allows assessing the extent of competitive pressure on the credit market.

On the basis of used methods of quantitative analysis we've developed several indicators to estimate the degree of herd behavior of commercial banks. These indicators are significant when determining the level of rationality on the credit market in part of assessing the balance between differenet sources of information processed by credit instittutions when granting loans. We also conducted a cross-country research, which allowed us to reveal the existence of regularities in development of credit markets, and to form a number of threshold values for its evaluation. The use of these indicators among other methods can contribute to optimizing the management of credit risk in corporate loan portfolio of the commercial bank, through achieving a balance between uses sources of information when making decisions on differenct credit proposals. In other words, when deciding on the borrower's potential to repay the debt one needs to pay attention not so much to the actions of other players, but to the qualitative analysis of his financial and economic activities. Perhaps the use of elaborated indicators could make a certain contribution to the development of methods of credit risk management in commercial bank as well as to achieving stability of credit market development.

\section{References}

Stiglitz J. \& Weiss A. (1981). Credit Rationing in Markets with Imperfect Information. The American Economic Review, 71(3), 393-410.

Burakov, D.V. (2014a). Exogenous Credit Cycles: an Experimental Study. World Applied Sciences Journal, 26(6), 733-736.

Burakov, D.V. (2014b). Does Framing Affect Risk Attitude: Experimental Evidence from Credit Market. American Journal of Applied Sciences, 11(1), 391-395.

Burakov, D.V. (2014c). Sources of Credit Cyclicity: A Theoretical Literature Overview. Review of European Studies, 6(1), $151-159$.

Burakov, D.V. (2014d). Limited Liability, Bank Capital and Credit cycles. A Behavioral Economic Approach. Middle East Journal of Scientific Research, 21(1), 28-32.

Kahneman, D. \& Tversky, A. (2008). Choices, Values and Frames. Cambridge University Press, pp: 840.

Rötheli, T.F. (2012). Boundedly Rational Banks' Contribution to the Credit Cycle. Journal of Socio-Economics, 41(5), 730-737.

Haldane, A. (2010). Curbing the Credit Cycle. Speech presented at the Columbia University Center on Capitalism and Society Annual Conference, New York.

Banerjee, Abhijit V. (1992). A Simple Model of Herd Behavior. Quarterly Journal of Economics, 107 (3), 797-817.

Raafat, R. M., Chater, N., Frith, C. (2009). Herding in humans. Trends in Cognitive Sciences, 13 (10), 420-428.

Hwang, S., \& Salmon, M. (2001). A New Measure of Herding and Empirical Evidence. A working paper, Cass Business School, U.K. Scharfstein, D.S. \& Stein, J.C. (1990). Herd Behavior and Investment. The American Economic Review, 80(3), 465-479. 